\title{
TRANSTORNO DO ESPECTRO AUTISTA: UM DESAFIO INCLUSIVO
}

\author{
Andrea Neves da Silva ${ }^{1}$
}

\section{RESUMO}

Com o avanço das políticas inclusivas no meio educativo, é cada vez mais comum que as unidades escolares recebam alunos diagnosticados com algum tipo de necessidade específica. Dessa forma, a presente pesquisa objetiva analisar como ocorre a inclusão de alunos com Transtorno do Espectro Autista nas salas de aula. O problema que fomentou este estudo foi de que os profissionais de educação nem sempre sabem como lidar com a inclusão de alunos com Transtorno do Espectro Autista e, inclusive, não recebem nenhum orientativo para isso. Para verificar essa situação, foram coletados dados bibliográficos em diversas plataformas de pesquisa e foram analisados qualitativamente. Com essa pesquisa, busca-se publicizar uma situação que, por vezes, é silenciada dentro das escolas sob a justificativa de não haver o que fazer com esses alunos diagnosticados com Transtorno do Espectro Autista.

Palavras-chave: Transtorno do Espectro Autista; Inclusão; Profissionais de Educação.

\begin{abstract}
With the advancement of inclusive policies in the educational environment, it is increasingly common for school units to receive students diagnosed with some type of specific need. Thus, this research aims to analyze how the inclusion of students with Autism Spectrum Disorder occurs in classrooms. The problem that fostered this study was that education professionals do not always know how to deal with the inclusion of students with Autism Spectrum Disorder and, in fact, do not receive any guidance for this. To verify this situation, bibliographic data were collected on several research platforms and were analyzed qualitatively. With this research, we seek to publicize a situation that is sometimes silenced within schools on the grounds that there is nothing to do with these students diagnosed with Autism Spectrum Disorder.
\end{abstract}

Keywords: Autistic Spectrum Disorder; Inclusion; Education Professionals.

\section{RESUMEN}

Con el avance de las políticas inclusivas en el ámbito educativo, es cada vez más común que las unidades escolares reciban alumnos diagnosticados con algún tipo de necesidad específica. Así, esta investigación tiene como objetivo analizar cómo se produce la inclusión de estudiantes con trastorno del espectro autista en las aulas. El problema que impulsó este estudio fue que los profesionales de la educación no siempre saben cómo lidiar con la inclusión de estudiantes con Trastorno del Espectro Autista y, de hecho, no reciben ninguna orientación para ello. Para verificar esta situación, se recopilaron datos bibliográficos en varias plataformas de investigación y se analizaron cualitativamente. Con esta investigación buscamos dar a conocer una situación que a veces se silencia dentro de las escuelas con el argumento de que no hay nada que ver con estos estudiantes diagnosticados con Trastorno del Espectro Autista.

Palabras clave: Trastorno del Espectro Autista; Inclusión; Profesionales de la Educación.

${ }^{1}$ Possui graduação em Pedagogia pelo Centro Universitário Moacyr Sreder Bastos (2006) e especialização em Gestão Escolar: Orientação e Supervisão na Área de Educação pelo Centro Universitário Barão de Mauá (2014). Atualmente, é Professor II da Prefeitura da Cidade do Rio de Janeiro. 


\section{INTRODUÇÃO}

O presente trabalho aborda o Transtorno do Espectro Autista e a inclusão, apresentando abordagens histórico-sociais, políticas e pedagógicas que possibilitem incluir e auxiliar os educandos com espectros autistas no universo escolar; respeitando suas particularidades, incentivando-os no aprendizado de novos conhecimentos, e buscando o auxílio da equipe multidisciplinar para dar suporte ao fazer um acompanhamento através de avaliações pertinentes e contínuas; da família que tem o dever de assumir o compromisso de cuidar; e da comunidade que precisa respeitar e acolher os indivíduos independentemente de suas diferenças.

Sabe-se que, desde a infância, os educandos especiais encontram sérias dificuldades no momento da aprendizagem devido às nuances de distúrbios / transtornos que possuem. Mas, ao encontrarem apoio familiar e educacional, a tarefa de aprender consegue ter diversos avanços, tornando-se completamente possível dentro de suas particularidades, além de mais fácil, prazerosa e promotora de confiança.

Para superar os desafios da inclusão no sistema educacional é necessária a presença do psicopedagogo no processo ensino-aprendizagem dos alunos especiais, e os docentes precisam estar capacitados. Em geral, isso significa definir metas e atividades, prestando atenção aos pontos fortes e fracos de cada aluno.

Segundo Paulo Freire (1996), aprender a ler, a escrever, alfabetizar-se é, antes de tudo, aprender a ler o mundo, compreender o seu contexto; não deve ser uma manipulação mecânica de palavras, mas numa relação dinâmica que vincula linguagem e realidade; assim deve ser em qualquer processo de aprendizagem. Sabe-se que educar para a sociedade exige mais do que a transmissão de conhecimentos, por mais relevantes e atualizados que alguns estejam; é necessário que em tal processo todos sejam incluídos.

Assim sendo, deve existir uma flexibilização na prática pedagógica utilizada para incluir a criança com necessidades especiais ao ambiente escolar de maneira significativa; uma vez que a escola, enquanto espaço democrático, jamais poderá permitir qualquer tipo de exclusão/discriminação. A cada momento, surgem novas ideias e desafios a serem superados por todos. 
Neste estudo, serão apresentados métodos que promovam a inclusão das crianças no ambiente escolar; evidenciando historicamente as propostas que colaboram para transformar práticas pedagógicas em resultados positivos e transformadores; determinando como o docente pode se adaptar às diferentes condições e, em conjunto com a equipe pedagógica, reconhecer estratégias para desenvolver um bom ensino-aprendizado para os educandos com Transtorno do Espectro Autista.

A pesquisa é relevante para proporcionar aos educandos especiais novas abordagens de inclusão desde a Educação Infantil; tornando este processo natural e promissor a todos os envolvidos, pois a Lei de Diretrizes e Bases da Educação LDB (9394/96), em seu artigo V, afirma que a educação de pessoas especiais deve ser oferecida na rede regular de ensino, contribuindo, desta forma, para uma melhor integração dessa pessoa na sociedade.

$O$ acervo utilizado será bibliográfico: livros, sites e artigos em geral para relatar os procedimentos pedagógicos, indicados pela literatura da área de educação especial e inclusiva; abordando as dificuldades dos discentes com Transtorno do Espectro Autista; investigando alguns métodos que promovam a aprendizagem desses infantes que necessitam ser acompanhados por psicopedagogos conforme consta na Lei de Diretrizes e Bases da Educação 9.394/96; além de apresentarem propostas de resolução de problemas pontuais.

Este material fundamenta-se na Lei de Diretrizes e Bases da Educação (LDB), nos Parâmetros Curriculares Nacionais (PCN's), em Cunha (2017), Freire (1996), Rodrigues; Spencer (2010), Whitman (2015), entre outros, que propõem realizar o processo de inclusão, direcionando o professor em sua prática pedagógica de maneira que os alunos especiais sejam amparados por lei, pois encaixam-se no perfil de alunos com NEE (Necessidades Educacionais Especiais) e devem ter seus direitos e garantias no ambiente escolar; entendendo que somente com uma atuação conjunta entre professores, equipe pedagógica e família será possível superar dificuldades relacionadas à inclusão.

\section{CONCEITUANDO O TRANSTORNO DO ESPECTRO AUTISTA (TEA)}

O autismo é um Transtorno Global do Desenvolvimento e é chamado de Transtorno do Espectro Autista (TEA); caracterizado por alterações significativas

Tendências Multidisciplinares: Investigação, Método e Ciência 
na comunicação, na interação social e no comportamento de qualquer pessoa que seja autista. Conforme Varella (2011),

\begin{abstract}
Autismo é um transtorno global do desenvolvimento marcado por três características fundamentais inabilidade para interagir socialmente; dificuldade no domínio da linguagem para comunicar-se ou lidar com jogos simbólicos; padrão de comportamento restritivo e repetitivo.

De acordo com o quadro clínico, eles podem ser divididos em 3 grupos: 1) ausência completa de qualquer contato interpessoal, incapacidade de aprender a falar, incidência de movimentos estereotipados e repetitivos, deficiência mental;

2) o portador é voltado para si mesmo, não estabelece contato visual com as pessoas nem com o ambiente; consegue falar, mas não usa a fala como ferramenta de comunicação (chega a repetir frases inteiras fora do contexto) e tem comprometimento da compreensão;

3) domínio da linguagem, inteligência normal ou até superior, menor dificuldade de interação social que permite aos portadores levar vida próxima do normal (VARELLA, 2011, p. 1).
\end{abstract}

\title{
É importante mencionar que essas alterações levam a importantes
} dificuldades adaptativas e aparecem antes dos três anos de idade, podendo ser percebidas, em alguns casos, nos primeiros meses de vida. As causas ainda não estão claramente identificadas, porém já se sabe que o autismo é mais comum em crianças do sexo masculino e independente da etnia, origem geográfica ou situação socioeconômica.

Essas crianças possuem dificuldades para interagir em grupos sociais. Sabe-se que uma tendência natural do ser humano é a de procurar uma identificação em alguém ou em alguma coisa; então, quando uma pessoa se identifica com outra, passa a estabelecer um vínculo social com ela, ocorre uma associação humana; os autistas não reagem assim.

A cada momento surgem novas ideias e desafios a serem superados por todos. Porém, o autista é indiferente a essas trocas de experiência; normalmente tudo isso o incomoda, inclusive se ele sair da rotina. Segundo Levin (2007),

A atividade e o brincar surgem na clínica psicomotora para que a criança se manifeste de forma espontânea, externalizando livremente seu desejo e suas possibilidades de fazer. É na transferência, fundamento da análise do espontâneo, onde se coloca em jogo o desejo da criança, onde o brincar do corpo, o seu posicionamento corporal é dado ao ver ao olhar da psicomotricidade.(...) Levin utiliza o conceito de Freud, sobre transferência: Reedições ou repetições dos impulsos e fantasias que hão de ser despertados e transformados em conscientes no desenvolvimento de uma análise e que entranham como particularidade e característica da sua espécie a substituição de uma pessoa anterior pela pessoa do médico, ou para dizê-lo de outro modo: toda uma série de processos psíquicos ganha vida novamente, 
porém, não mais como sendo pertencentes ao passado, e sim como relação atual na pessoa do médico (LEVIN, 2007, p. 122).

De acordo com Giannini (2018), os casos de autismo são cada vez mais frequentes. Um recente relatório do Centro de Controle e Prevenção de Doenças (CDC), dos Estados Unidos, relata que houve um aumento de 15\% no quantitativo de crianças com autismo em relação aos dois anos anteriores.

No Manual Diagnóstico e Estatístico de Transtornos Mentais - DSM-V o autismo apresenta-se como "déficits persistentes na comunicação social e na interação social em múltiplos contextos" (WHITMAN, 2015, p. 40)

O DSM-V define os sintomas do autismo, que são definidos basicamente em problemas de interação social, comunicação e comportamento. Segundo o mesmo autor (op. cit), para que seja concluído o quadro de autismo, é necessário que a criança apresente no mínimo seis sintomas do DSM-V. Alerta também que cada caso de criança com TEA é singular, pois os graus, comportamentos e respostas às intervenções são diferentes entre os indivíduos.

Segundo Cunha (2017, p. 20), o autismo apresenta uma tríade de principais sintomas que comprometem a comunicação, a socialização e o comportamento. Os sinais podem aparecer já nos primeiros meses, mas tornase mais visível por volta dos três anos de idade. De acordo com este autor (op. cit.), existem sintomas que quando percebidos precocemente na criança auxiliam o diagnóstico: não interage com os que estão próximos; não estabelece contato visual; oraliza pouco ou o faz de forma limitada; inflexível às mudanças na rotina; estereotipia (repetição de gestos, palavras ou movimentos); ecolalia (repetição da fala de outra pessoa); calma exacerbada; agitação demasiada; apego ou manipulação de objetos de maneira inapropriada; ausência de sentimentos de dor, perigo ou medo; e não responde quando chamado; sensibilidade aos sons.

Estes são apenas uma parte dos sintomas que podem indicar que a criança tenha autismo. É importante que os pais / responsáveis e a escola fiquem atentos a quaisquer comportamentos inapropriados para a idade do indivíduo. Na maioria dos casos, a observação parte da escola, que ao perceber, deve notificar aos responsáveis para que as investigações sejam iniciadas. $O$ diagnóstico deve ser com muito cuidado para que não ocorram equívocos ou erros. 
Segundo Orrú (2012):

\begin{abstract}
Para o diagnóstico de autismo, pode ser utilizado um vasto protocolo de investigação, a partir da realização de exames para pesquisa de possíveis condições específicas, geneticamente determinadas ou não, de realização de pelo menos um dos exames de neuroimagem propostos, e fazendo uso de agrupamento de alguns critérios do DSMIV (APA, 1995) e da CID-10 (OMS, 1993), além de anamnese detalhada, exame físico, dando atenção aos sinais comumente associados a cromossopatias e a outras afecções de etiologia genética, avaliação neuropsicológica, análise bioquímica para erros do metabolismo, exames de cariótipo, eletroencefalograma, ressonância magnética de crânio, SPECT, além de outros possíveis exames complementares (ORRÚ, 2012, p. 26).
\end{abstract}

É de suma importância que a investigação seja detalhada, buscando saber sobre a família, a gestação, como se deram os desenvolvimentos esperados para a faixa etária e a estimulação oferecida pelo ambiente em que convive.

O psicopedagogo deve, com autoridades competentes, refletir e elaborar a organização, a implantação e a execução de projetos de Educação e Saúde no que concerne às questões psicopedagógicas (CÓDIGO DE ÉTICA, 1996, Artigo $4^{\circ}$, p. 2).

\title{
CONCEITUANDO A INCLUSÃO DE ALUNOS COM TEA NA EDUCAÇÃO BÁSICA
}

Em 1994, na Espanha, foi proclamada a Declaração de Salamanca que deliberou a respeito do direito ao acesso à educação por parte das pessoas com deficiência, onde os governos se comprometeram em elaborar medidas para que estas crianças e jovens, antes excluídos da escola, integrassem no sistema educacional por meio do sistema regular de ensino, quando não possível, devendo ser garantido o ingresso na educação especial específica.

A Declaração de Salamanca define importantes concepções para o acesso e permanência da pessoa com necessidades educacionais especiais. Logo no começo, ela determina que a educação é um direito de toda criança, o que já de início quebra a arcaica ideia de que crianças com deficiência não deveriam frequentar a escola.

Em seguida, a Declaração de Salamanca estabelece que indivíduos com necessidades educacionais especiais têm direito ao ingresso em escolas 
regulares de Educação Básica, e que a educação deve ser pensada e implantada de forma que considere as diferenças, bem como as particularidades, preferências e dificuldades de cada discente, além disso, é dado o direito a desfrutarem de circunstâncias que o permitam alcançar o ponto máximo de aprendizagem.

Entende-se que este documento defende que a escola deve se adaptar à maneira de aprender das crianças, contrariando teorias tradicionais de ensino em que o discente deve se adaptar ao modelo de aprendizagem imposto pela escola. Declara também que sempre que viável, todas as crianças precisam aprender simultaneamente, assim, o ensino educacional especializado só deve ser disponibilizado ao aprendente quando a classe regular não amparar as necessidades educacionais e sociais apresentadas por ele.

Para a Declaração de Salamanca, a Escola Inclusiva deve adaptar o currículo, planejar estratégias de ensino e elaborar melhorias nas estruturas organizacionais, pois assim, os indivíduos com necessidades especiais poderão desenvolver-se nos aspectos educacionais e sociais, além de influenciar para o exercício da solidariedade entre as crianças com necessidades especiais e as demais presentes no ambiente escolar.

Constata-se que a inclusão, antes de qualquer coisa, é um direito previsto em lei para as crianças e adolescentes com deficiência, sejam de natureza física, mental, intelectual ou sensorial. No entanto, apenas colocar esse indivíduo dentro de uma sala de aula regular sem que haja planejamentos, estratégias e objetivos pré-estabelecidos não é promover verdadeiramente uma inclusão, nesse caso, haverá apenas uma integração.

Então, no processo inclusivo, os professores devem desenvolver estratégias para que os alunos aprendam em conjunto com os outros, promovendo assim um espaço de aprendizagem igualitário. Como já dito, a inclusão é um direito, no entanto, é preciso muito mais que conhecer a lei; a escola deve colocar em prática a legislação, comprometendo-se a proporcionar estratégias que estimulem ao máximo o desenvolvimento de cada aluno.

Segundo Cunha (2009), a chave para a aprendizagem é o amor. Dessa forma, entende-se que para uma inclusão efetiva, é necessário antes de tudo, que o professor tenha amor pelo trabalho que faz. 
Podemos dizer que todo conhecimento que vem pelo amor possui a excelência da perfeição. Acima de tudo, quem aprende e quem ensina precisa antes do amor. Na verdade, todo conhecimento possui também a culminância da distinção quando se designa ao amor. O amor é a sublimação do saber (CUNHA, 2009, p. 115).

Alves (2001), abordou na obra sobre a Escola da Ponte, situada em Portugal, informações sobre as escolas que seguem um modelo de linha de montagem apenas transferindo conhecimentos prontos e descartando aqueles que ao final do processo não seguiram o modelo determinado.

Portanto, ponderando sobre o pensamento de Cunha (2009) e Alves (2001), conclui-se que é necessário romper com o ensino tradicional que valoriza apenas os que se adaptam bem ao seu padrão, e incorporar o amor a todo processo educativo valorizando todos os indivíduos, respeitando as individualidades e promovendo um espaço igualitário e participativo.

\section{ATENDIMENTO EDUCACIONAL ESPECIALIZADO EM SALA DE RECURSOS}

Sabe-se que quando a criança inicia sua vida escolar precisa ser bem recebida por todos. O lugar deve ser confortável, despertar interesses, ser desafiador, amparar emocionalmente o educando, pois somente assim, haverá interação do aluno com o meio em que estará inserido; resultando num aprendizado qualitativo e contextualizado.

Conforme os Parâmetros Curriculares Nacionais (1998, p. 43), "O acolhimento requer compromisso político com a educação manifestado em uma série de medidas concretas que, embora não sejam de responsabilidade exclusiva das escolas, precisam ser assumidas por elas".

Sobre esse aspecto, o mesmo documento assim disserta:

(...) a escola ainda se mostra um espaço atraente para os adolescentes e jovens pela possibilidade do encontro com outros jovens, pois essa é a experiência que consideram mais positiva na escola. Os corredores, pátios, banheiros e portões transformam-se em espaços privilegiados de convivência e, por isso mesmo, os espaços mais interessantes, particularmente para os jovens dos setores populares, que não dispõem de espaços - e, muitas vezes, nem de tempo propícios ao lazer e ao encontro com seus pares. Essa experiência é vivida de forma paralela à escola que, geralmente, não considera importante a vivência da sociabilidade juvenil e simplesmente a consente (quando não procura dificultá-la ou impedi-la). Algumas escolas reconhecem a importância da convivência e procuram favorecê-la, fazendo com que os adolescentes e jovens se apropriem 
do espaço escolar e reforcem os laços de identificação com a escola (BRASIL, 1998, p. 125).

Sendo assim, a escola precisa disponibilizar um ambiente propício: a Sala de Recursos, a qual deve estar adequada a receber e acolher os educandos, independentemente de suas classes sociais e limitações; salvo casos de crianças/jovens que possuam laudos médicos que impossibilitem o convívio escolar.

Segundo Villela e Archangelo (2013), o professor deve conhecer seu aluno, bem como seus interesses, compreendendo-o em sua individualidade, dessa maneira a criança poderá sentir que o docente se importa com ela, o que conduzirá que este sinta confiança no educador, o que também vem a ser uma manifestação de afetividade. Assim, com afeto e paciência o desenvolvimento da criança autista será progressivo e constante.

Crianças no espectro do autismo geralmente têm dificuldades com estilos de aprendizagem visuais ou auditivos. A sala de recurso deve ofertar opções de jogos, mídias; entre outros recursos para que os professores atendem ao estilo de aprendizagem específico de cada criança autista. Para alunos visuais, uma combinação de literatura, vídeos, fotos e gráficos retransmitem melhor as informações da lição. Alunos auditivos geralmente requerem uma fita de áudio ou gravação das informações escritas para a aula.

\footnotetext{
Programa disponibiliza às escolas públicas de ensino regular, conjunto de equipamentos de informática, mobiliários, materiais pedagógicos e de acessibilidade para a organização do espaço de atendimento educacional especializado. Cabe ao sistema de ensino, a seguinte contrapartida: disponibilização de espaço físico para implantação dos equipamentos, mobiliários e materiais didáticos e pedagógicos de acessibilidade, bem como, do professor para atuar no AEE (BRASIL, 2007).
}

Neste mesmo ambiente, é possível oferecer ferramentas táteis para transmitir as informações fornecidas em cada lição; tais ferramentas podem ser flashcards, jogos de tabuleiro, blocos para anotações, jogos de computador e projetos de artesanato. Ressaltando que é benéfico para os alunos experimentarem outros tipos de mídia também; o melhor progresso será feito com o estilo de aprendizagem preferido pela criança. 
Sabe-se que nem todas as crianças autistas são iguais; enquanto uma pode ter limitações para ouvir, outra pode não ter. É por isso que é importante facilitar recursos variados. As crianças que possuem problemas de audição podem precisar de alguns fones de ouvido para ficar mais confortável compreender e participar da aprendizagem.

Quando a sala de recursos for utilizada para tarefas coletivas, como por exemplo, quando outros alunos estiverem assistindo a um vídeo, os fones de ouvido podem ser conectados ao computador ou à TV para permitir que as crianças autistas também ouçam no volume adequado para elas e sem intervenção sonora. Existem vários dispositivos diferentes para ajudar as pessoas com autismo.

Ainda sobre o ambiente da sala de recursos, é possível adequá-la com tipos variados de ferramentas sensoriais adequadas, incluindo bolas antiestresse, quebra-cabeças emaranhados, argila, almofadas giratórias, almofadas abdominais ponderadas, faixas para cadeiras e rodinhas. Uma vez que inquietações são divertidas e uma boa opção para ter à disposição de todos os alunos evitando que alguém se sinta excluído.

Este mesmo local pode ser para alunos descansarem confortavelmente e permitir que seu sistema sensorial se acalme ao ler um livro ou ouvir uma música bem tranquila. $O$ professor e mediador deve proporcionar momentos tranquilos e intervalos entre as atividades para fornecer o tempo necessário para a transição entre as tarefas e a recuperação das demandas do ambiente da sala de recursos.

As pausas também devem estar disponíveis conforme a necessidade para permitir que os alunos com autismo aprendam como responder às dicas internas e realizar as ações necessárias para regular seu ser. Entendendo que não há um número específico de pausas, pois caso contrário, os alunos podem ficar propensos a colapsos por sobrecarga sensorial e fadiga por tentarem se regular constantemente às regras impostas.

O docente mediador pode sugerir pausas extras no início das atividades para ajudar a criança a se conscientizar de seus sentimentos / vontades. Os intervalos guiados também dão às crianças a chance de ver quais atividades do intervalo oferecem os maiores benefícios. Crianças que buscam estímulos 
podem preferir ouvir música, enquanto alunos sobrecarregados podem se beneficiar trabalhando em silêncio com um quebra-cabeça.

Sempre haverá oportunidades para o mediador personalizar ainda mais a sala de recursos mitigando os desafios que as crianças autistas enfrentam na escola. À medida que o professor navega no processo de fornecer suporte ao educando autista, deve propiciá-lo os recursos disponíveis para criar um ambiente de aprendizagem amigável e acolhedor.

\section{ATENDIMENTO EDUCACIONAL ESPECIALIZADO PARA CLASSES REGULARES}

No art. 206, do Estatuto da Criança e Adolescente, promulga o direito de todos à educação e a permanência na escola de forma igualitária; no art. 208, dispõe a respeito do direito ao atendimento educacional especializado para os portadores de necessidades especiais, dando preferência a esses, no ensino regular.

Além do ECA, outra lei que garante direitos às crianças e adolescentes é a Lei de Diretrizes e Bases tendo sua primeira versão publicada em 1961, pelo então presidente João Goulart, ganhando nova versão em 1971, valendo até 1996 quando foi promulgada uma versão mais recente.

A LDB reforça os direitos garantidos pela constituição a partir do art. $58 \mathrm{e}$ pelo ECA nos artigos 205 e 208. Porém, a LDB discorre mais especificamente a respeito das pessoas com deficiências.

No art. 4 inciso III, a LDB declara que é de direito o acesso ao atendimento educacional especializado aos alunos que apresentem deficiência, transtornos globais do desenvolvimento, altas habilidades ou superdotação, sendo essa determinação válida para todos os níveis da educação.

A partir destas leis, compreende-se primeiramente que toda e qualquer criança, independentemente de ser portadora de alguma deficiência ou transtorno, tem o direito à educação; e aos que possuem deficiência, transtornos globais do desenvolvimento, altas habilidades e superlotação devem ser disponibilizados $\mathrm{o}$ atendimento educacional especializado, que será voltado a desenvolver um trabalho diferenciado que seja direcionado às reais necessidades destes educandos. 
Todo esse processo constitui um dever do Estado e direito da família e da criança, que respaldado pela finalidade da educação descrita no art. 2 da LDB determina o objetivo final: "o pleno desenvolvimento do educando", assim, cabe à escola adequar-se às diversas necessidades.

De acordo com Cunha (2009) é indispensável o acesso ao atendimento educacional especializado e, também, o acesso à classe regular de ensino. Sabe-se que, em alguns casos, modificações terão que ser feitas durante 0 processo de ensino-aprendizagem e adaptação desse indivíduo, e a respeito disso, o art. 59 na LDB traz importantes determinações para o desenvolvimento e sucesso desses alunos.

No art. 29, a LDB determina que a educação infantil deve desenvolver a criança nos aspectos psicológicos, sociais, intelectuais e físicos, de maneira que complemente as ações da família e da comunidade. Assim, é possível compreender que o desenvolvimento das crianças também é um dever da família e da comunidade, as quais precisam estabelecer parcerias com a escola para que ocorra o desenvolvimento sadio e integral dos envolvidos.

De acordo com o Plano Nacional de Educação, na meta quatro, é disposto a respeito do direito de acesso à educação básica de crianças e adolescentes portadores de deficiências, altas habilidades ou superdotação. Além disso, garante também que:

[...] atendimento educacional especializado, preferencialmente na rede regular de ensino, com a garantia de sistema educacional inclusivo, de salas de recursos multifuncionais, classes, escolas ou serviços especializados, públicos ou conveniados (PNE, 2014, p. 11).

Na estratégia 1.11 da meta um do PNE, é determinado que a partir da educação infantil seja garantido o acesso ao atendimento educacional especializado complementar e suplementar às crianças com deficiência, altas habilidades ou superdotação. Em seguida, é articulada uma estratégia muito relevante, cujo objetivo é atender às famílias, de modo a oferecer orientação, e às crianças de até três anos com objetivo de estimular o desenvolvimento integral destes. De acordo com a estratégia citada, essas ações devem ser executadas por meio da junção das áreas de educação, saúde e assistência social. 


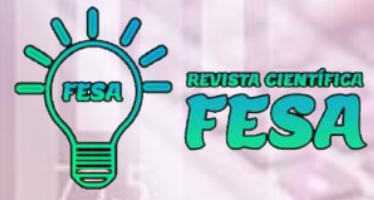

A partir de todas as leis e planos expostos que determinam a garantia de acesso à educação e ao atendimento educacional especializado, conclui-se que os indivíduos com o transtorno do espectro autista, assim como quaisquer crianças, possuem o direito de frequentarem classe regular e terem a oferta de uma educação de qualidade, e que apesar de suas limitações sejam estimulados a se desenvolverem de acordo com o que determina a lei.

Além disso, é concedido à família destes o direito à orientação, e a esses educandos mecanismos de desenvolvimento por meio da saúde, educação e assistência social.

Portanto, é necessário que todos - família, comunidade, professores etc. - tenham conhecimento das leis, a fim de que a educação, inclusão e desenvolvimento sejam garantidos às crianças com autismo. Dessa forma, de fato eles terão direito a uma educação de qualidade que respeita as individualidades, dificuldades e limitações; buscando caminhos para que estes não sejam impossibilitados de aprenderem, se desenvolverem e desempenharem papéis dignos de cidadãos autônomos.

De acordo com Bombonatto (2010), no Código de Ética da psicopedagogia estão informações sobre a área do conhecimento responsável por abordar o processo de aprendizagem, investigar as causas das dificuldades e conhecer a história de vida dos indivíduos considerando a esfera emocional, social, familiar, cultural etc., visando saber como o sujeito aprende.

Durante a intervenção psicopedagógica, o psicopedagogo deve considerar os processos de aprendizagem e os diferentes ambientes expostos a essa criança ou adolescente. A aprendizagem humana constitui-se como objeto de estudo da psicopedagogia, cujo trabalho desenvolvido deve ser mantido em sigilo, salvo em casos de repasse de informações às instituições vinculadas ao indivíduo atendido, com autorização dos responsáveis, ou em caso de intimação judicial, como determina o sétimo artigo do Código de Ética.

A Associação Brasileira de Psicopedagogia define no terceiro artigo os objetivos para a prática desse profissional no processo de inclusão; elaborar intervenções para os processos de aprendizagem e dificuldade; auxiliar na inclusão escolar e social; desempenhar pesquisas científicas na área em questão; prevenir as dificuldades de aprendizagem e/ou conflito, intermediando as relações entre os indivíduos.

Tendências Multidisciplinares: Investigação, Método e Ciência 


\section{ATENDIMENTO EDUCACIONAL ESPECIALIZADO EM CONSULTÓRIOS MÉDICOS}

Após ser identificado como autista, é necessário iniciar o acompanhamento clínico para haver mais qualidade de vida para o paciente e sua família, que até então, normalmente, tinha dificuldades para lidar com tal situação. Estabelecer uma boa relação entre o autista e os profissionais da área médica é indispensável para a eficácia do tratamento; devem existir confiança, afeto, entre outras conquistas que serão percebidas no dia a dia, pois a criança vai aprendendo a reagir a diversos estímulos.

Tudo isso se torna mais fácil após o diagnóstico de uma equipe especializada, incluindo o psicopedagogo durante todo o processo. Segundo Varella (2011):

O diagnóstico é essencialmente clínico. Leva em conta o comprometimento e o histórico do paciente e norteia-se pelos critérios estabelecidos por DSM-IV (Manual de Diagnóstico e Estatística da Sociedade Norte-Americana de Psiquiatria) e pelo CID-10 (Classificação Internacional de Doenças da OMS) (VARELLA, 2011).

Então, o quanto antes for diagnosticado, será de suma importância o acompanhamento e o avanço no desenvolvimento sensório-motor, linguístico e físico. Ainda, segundo o mesmo autor (op. cit.),

Até o momento, autismo é um distúrbio crônico, mas que conta com esquemas de tratamento que devem ser introduzidos tão logo seja feito o diagnóstico e aplicados por equipe multidisciplinar.

Não existe tratamento padrão que possa ser utilizado. Cada paciente exige acompanhamento individual, de acordo com suas necessidades e deficiências. Alguns podem beneficiar-se com 0 uso de medicamentos, especialmente quando existem comorbidades associadas (Idem., 2011).

E, também, 
* Autistas têm dificuldade de lidar com mudanças, por menores que sejam; por isso é importante manter o seu mundo organizado e dentro da rotina;

* Apesar de a tendência atual ser a inclusão de alunos com deficiência em escolas regulares, as limitações que o distúrbio provoca devem ser respeitadas. Há casos em que o melhor é procurar uma instituição que ofereça atendimento mais individualizado;

* Autistas de bom rendimento podem apresentar desempenho em determinadas áreas do conhecimento com características de genialidade (Ibidem., 2011).

Sendo assim, é dever da família acompanhar o autista e proporcioná-lo um suporte emocional e social como referência desde o seu nascimento; criando um vínculo indissociável. E, em conjunto com o suporte médico, suprir tudo o que for necessário para uma vida mais tranquila e equilibrada; lembrando que isso não exclui a responsabilidade que a sociedade também possui.

As premissas para atuação dos profissionais de psicopedagogia que, no Brasil, são os portadores de certificado em curso de especialização, expedido nos termos da lei, são diversas e abarcam contribuir nos aspectos educacionais como atendimentos em clínicas. Conforme Rubinstein (2001),

\begin{abstract}
A intervenção psicopedagógica focaliza o sujeito na sua relação com a aprendizagem. A meta do psicopedagogo é ajudar aquele que, por diferentes razões, não consegue aprender formal ou informalmente, para que consiga não apenas interessar-se por aprender, mas adquirir ou desenvolver habilidades necessárias para tanto [...] (RUBINSTEIN, 2001, p. 25).
\end{abstract}

Assim sendo, o psicopedagogo precisa ter conhecimento em diversas áreas para fazer avaliações pertinentes e contínuas para diferenciar dificuldades e transtornos cognitivos diversos. Pode-se evidenciar que a função desses profissionais se estende no campo do serviço clínico e social por propiciar a interações entre paciente, seus familiares e demais pessoas que estão próximas. Segundo Varella (2011),

O diagnóstico é essencialmente clínico. Baseia-se nos sinais e sintomas e leva em conta os critérios estabelecidos por DSM-IV (Manual de Diagnóstico e Estatística da Sociedade Norte-Americana de Psiquiatria) e pelo CID-10 (Classificação Internacional de Doenças da OMS), o comprometimento e o histórico do paciente (VARELLA, 2011). 
O Projeto de Lei no 3124/97 do Deputado Barbosa Neto regulamenta a profissão do Psicopedagogo e cria o Conselho Federal e os Conselhos Regionais de Psicopedagogia estabelecendo princípios norteadores:

Art. 10 É livre, em todo o território nacional, o exercício da atividade de Psicopedagogia, observadas as disposições desta lei. Art. $2^{\circ}$ Poderão exercer a profissão de Psicopedagogo no País: I - os portadores de certificado de conclusão em curso de especialização em Psicopedagogia, em nível de pós-graduação, expedido por escolas ou instituições devidamente autorizadas ou credenciadas nos termos da legislação pertinente; 11 - os portadores de diploma de curso superior que já venham exercendo ou tenham exercido, comprovadamente, atividades profissionais de Psicopedagogia em entidade pública ou privada e que requeiram, o respectivo registro no Conselho Regional de seu domicílio (NETO, 1997, p. 3).

Entre suas principais finalidades estão atenção nos âmbitos individual e coletivo, pois busca meios de considerar a integralidade do atendimento sem que este seja limitado apenas ao paciente; é necessário atuar com uma equipe de profissionais para haver diagnósticos e tratamentos corretos em que 0 psicopedagogo fará suas comunicações sempre de maneira bem clara e objetiva. A missão do psicopedagogo trata-se de um compromisso e uma responsabilidade social para com o cidadão que necessita de aprendizado / tratamento individualizado ou coletivamente havendo intercessão cuidadosa.

Segundo Pego (2003), é necessário "permitir a ocorrência da reelaboração criativa das experiências de seus pacientes de maneira que estes se coloquem, enquanto sujeitos capazes de usufruir o exercício dinâmico e fluído da ação de ensinante-aprendente."

A Associação Brasileira de Psicopedagogia - ABPp - criada a 20 anos, com sede em São Paulo, realiza vários congressos, encontros, atividades científicas; publica livros, uma revista periódica, jornais e boletins que circulam em todo o território nacional e Mercosul para divulgar a importâncias dos psicopedagogos. 
Consta, no Conselho Nacional da Associação Brasileira de Psicopedagogia, que a regulamentação da profissão dos psicopedagogos formados nas universidades brasileiras desde a década de sessenta, torna-se não só legítima, mas urgente.

Consta-se que de acordo com os princípios constitucionais da dignidade humana e os direitos legais; a perspectiva central da psicopedagogia é fornecer suporte necessário à saúde mental e ao aprendizado cognitivo. A atuação do psicopedagogo institucional e/ou clínico será determinante no sucesso ou fracasso no tratamento posterior ao diagnóstico.

\section{CONSIDERAÇÕES FINAIS}

A partir de todas as leis e planos expostos que determinam a garantia de acesso à educação e ao Atendimento Educacional Especializado, conclui-se que os indivíduos com o Transtorno do Espectro Autista, assim como quaisquer crianças, possuem o direito à educação em classes regulares de ensino e a uma formação de qualidade e que, apesar de suas limitações, devem ser estimulados a se desenvolverem de acordo com o que determina a lei.

De acordo com toda a pesquisa elaborada sobre a inclusão dos educandos com Transtorno do Espectro Autista (TEA), percebe-se que somente atuando com base nas leis, nas formações para a equipe docente e lidando diretamente com o educando portador de necessidades especiais é possível diagnosticar qual o caminho a seguir em cada atividade; observando o momento de avançar, retroceder ou readaptar a atividade proposta.

Assim, a equipe escolar, sob o viés de uma educação democrática e participativa, deve elencar suas perspectivas e estratégias, em primeiro plano, fazendo-se reconhecer através da efetiva inclusão do corpo discente. Para tal ação, é primordial que sejam utilizadas metodologias em consonância com o Projeto Político Pedagógico da unidade escolar, com os parâmetros da Lei de Diretrizes e Bases da Educação (LDB), dos Parâmetros Curriculares Nacionais (PCN'S), entre outros; e o constante acompanhamento do psicopedagogo institucional e/ou clínico, principalmente, porque o acompanhamento deve ser iniciado assim que houver a percepção de que a criança possui algum transtorno, 
déficit ou muita introspecção; com dificuldade de socialização; intolerância ao barulho ou mudanças no ambiente em que convive.

\section{REFERÊNCIAS BIBLIOGRÁFICAS}

ALVES, R. A Escola com que sempre sonhei sem imaginar que pudesse existir. Campinas, SP: Papirus, 2001.

BOMBONATTO, Q. Código de ética do psicopedagogo. Associação Brasileira de Psicopedagogia (ABPp), 2010. Disponível em: https://www.abpp.com.br/artigos/documentos referencias codigo etica.html. Acesso em 23 de out. de 2020.

BRASIL. Lei de Diretrizes e Bases da Educação Nacional. Lei n.ำ 9.394 de 20 de dezembro de 1996.

BRASIL. Secretaria de Educação Fundamental. Parâmetros Curriculares Nacionais: terceiro e quarto ciclos do ensino fundamental introdução aos parâmetros curriculares nacionais/ Secretaria de Educação Fundamental. Brasília: MEC/SEF, 1998.

BRASIL. Programa Implantação de Salas de Recursos Multifuncionais. (2007) Disponível em: http://portal.mec.gov.br/pet/194-secretarias112877938/secad-educacao-continuada-223369541/17430-programa-

implantacao-de-salas-de-recursos-multifuncionais-novo. Acesso em 18 de out. de 2020.

BRASIL. (PNEE) Nova Política Nacional de Educação Especial é lançada em Brasília. (2020) Disponível em: https://www.gov.br/pt-br/noticias/educacao-epesquisa/2020/09/nova-politica-nacional-de-educacao-especial-e-lancada-embrasilia Acesso em 22 de out. de 2020.

CUNHA, E. Autismo e Inclusão: psicopedagogia práticas educativas na escola e na família. Rio de Janeiro: Wak Ed., 2009.

CUNHA, E. Autismo na escola: um jeito diferente de aprender, um jeito diferente de ensinar - ideias e práticas pedagógicas. Rio de Janeiro: Wak Editora, 2017.

FREIRE, P. Pedagogia da Autonomia Saberes Necessários à prática educativa. 1996.

GIANNINI, Deborah. Aumenta número de crianças com autismo, segundo pesquisa, 2018. Disponível em: https://noticias.r7.com/saude/aumentanumero-de-criancas-com-autismo-segundo-pesquisa-27042018 Acesso em 18 de out. De 2020. 
LEVIN, E. A clínica psicomotora: o corpo na linguagem, 2007. Disponível em: http://www.faef.revista.inf.br/imagens arquivos/arquivos destaque/vzrPzX88UISehdi 2013-6-28-15-57-0.pdf. Acesso em: 22 de out. de 2020.

NETO, B. Dispõe sobre a regulamentação da profissão de Psicopedagogo, cria o Conselho Federal e os Conselhos Regionais de Psicopedagogia e determina outras providências, 2007. Disponível em: https://abpp.com.br/pl3124-1997.pdf. Acesso em 20 de out. de 2020.

ORRÚ, S. E. Autismo, linguagem e educação: interação social no cotidiano escolar. Rio de Janeiro: Wak, 2012.

PEGO, M. G. T. Psicopedagogia Online, 2003. Disponível em: www.psicopedagogia.com.br/artigos. Acesso em 16 de out. de 2020.

RODRIGUES, J. M. C.; SPENCER, E. A criança autista: um estudo psicopedagógico. Rio de Janeiro: Wak, 2010.

RUBINSTEIN, E. Regulamento da Profissão do Psicopedagogo. Revista Psicopedagógica. v. 19, n. 54, p. 25, 2001.

VARELLA, D. Distúrbio de Linguagem, 2011. Disponível em: www.drauziovarella.com.br. Acesso em 22 de out. de 2020.

VILLELA, F.; ARCHANGELO, A. Fundamentos da escola significativa. São Paulo: Ed. Loyola, 2013.

WHITMAN, T. L. O desenvolvimento do autismo. São Paulo: M. Books do Brasil Editora Ltda, 2015. 